University of Wollongong

Research Online

Faculty of Engineering and Information

Faculty of Engineering and Information

Sciences - Papers: Part A

Sciences

$1-1-2013$

Investigating straight-pipe pneumatic conveying characteristics for fluidized dense-phase pneumatic conveying

A Bansal

Thapar University, India

S S. Mallick

Thapar University, India, ssm672@uow.edu.au

P W. Wypych

University of Wollongong, wypych@uow.edu.au

Follow this and additional works at: https://ro.uow.edu.au/eispapers

Part of the Engineering Commons, and the Science and Technology Studies Commons

Research Online is the open access institutional repository for the University of Wollongong. For further information contact the UOW Library: research-pubs@uow.edu.au 


\title{
Investigating straight-pipe pneumatic conveying characteristics for fluidized dense-phase pneumatic conveying
}

\begin{abstract}
This article presents results from an investigation into the pneumatic conveying characteristics (PCC) for horizontal straight-pipe sections for fluidized dense-phase pneumatic conveying of powders. Two fine powders (median particle diameter: 30 and $55 \mathrm{um}$; particle density: 2300 and $1600 \mathrm{~kg} \mathrm{~m}$-3; loose-poured bulk density: 700 and $620 \mathrm{~kg} \mathrm{~m}-3$ ) were conveyed through $69 \mathrm{~mm}$ I.D. x $168 \mathrm{~m}, 69 \mathrm{~mm}$ I.D. x $148 \mathrm{~m}, 105$ $\mathrm{mm}$ I.D. $\times 168 \mathrm{~m}$ and $69 \mathrm{~mm}$ I.D. $\times 554 \mathrm{~m}$ pipelines for a wide range of air and solids flow rates. Straightpipe pneumatic conveying characteristics obtained from two sets of pressure tappings installed at two different locations in each pipeline have shown that the trends and relatively magnitudes of the pressure drops can be significantly different depending on product, pipeline diameter and length and location of tapping point in the pipeline (indicating a possible change in transport mechanism along the flow direction). The corresponding models for solids friction factor were also found to be different. There was no distinct pressure minimum curve (PMC) in any of the straight-pipe PCC, indicating a gradual change in flow transition (change in flow mechanism from dense to dilute phase). For total pipeline conveying characteristics, the shapes of the PCC curves and the location of the PMC were found to be significantly influenced by pipeline layout (e.g., location and number of bends) and not entirely by the dense-to-dilutephase transition of flow mechanism. Seven existing models and a new empirically developed model for PMC for straight pipes have been evaluated against experimental data.
\end{abstract}

\section{Keywords}

investigating, straight, pipe, dense, pneumatic, phase, conveying, characteristics, fluidized

\section{Disciplines}

Engineering | Science and Technology Studies

\section{Publication Details}

Bansal, A., Mallick, S. S. \& Wypych, P. W. (2013). Investigating straight-pipe pneumatic conveying characteristics for fluidized dense-phase pneumatic conveying. Particulate Science and Technology: an international journal, 31 (4), 348-356. 


\title{
Investigating Straight-Pipe Pneumatic Conveying Characteristics for Fluidized Dense-Phase Pneumatic Conveying
}

\author{
A. BANSAL, ${ }^{1}$ S. S. MALLICK, ${ }^{1}$ and P. W. WYPYCH ${ }^{2}$ \\ ${ }^{1}$ Department of Mechanical Engineering, Thapar University, Patiala, Punjab, India \\ ${ }^{2}$ Faculty of Engineering, University of Wollongong, Wollongong, New South Wales, Australia
}

This article presents results from an investigation into the pneumatic conveying characteristics (PCC) for horizontal straight-pipe sections for fluidized dense-phase pneumatic conveying of powders. Two fine powders (median particle diameter: 30 and $55 \mu \mathrm{m}$; particle density: 2300 and $1600 \mathrm{~kg} \mathrm{~m}^{-3}$; loose-poured bulk density: 700 and $620 \mathrm{~kg} \mathrm{~m}^{-3}$ ) were conveyed through $69 \mathrm{~mm}$ I.D. $\times 168 \mathrm{~m}, 69 \mathrm{~mm}$ I.D. $\times 148 \mathrm{~m}, 105 \mathrm{~mm}$ I.D. $\times 168 \mathrm{~m}$ and $69 \mathrm{~mm}$ I.D. $\times 554 \mathrm{~m}$ pipelines for a wide range of air and solids flow rates. Straight-pipe pneumatic conveying characteristics obtained from two sets of pressure tappings installed at two different locations in each pipeline have shown that the trends and relatively magnitudes of the pressure drops can be significantly different depending on product, pipeline diameter and length and location of tapping point in the pipeline (indicating a possible change in transport mechanism along the flow direction). The corresponding models for solids friction factor were also found to be different. There was no distinct pressure minimum curve (PMC) in any of the straight-pipe PCC, indicating a gradual change in flow transition (change in flow mechanism from dense to dilute phase). For total pipeline conveying characteristics, the shapes of the PCC curves and the location of the PMC were found to be significantly influenced by pipeline layout (e.g., location and number of bends) and not entirely by the dense-to-dilute-phase transition of flow mechanism. Seven existing models and a new empirically developed model for PMC for straight pipes have been evaluated against experimental data.

Keywords: Dense phase, pneumatic conveying, pressure drop, pressure minimum curve, straight-pipe conveying characteristics

\section{Introduction}

Dense-phase pneumatic conveying of powders is becoming increasing popular in various industries such as coal-fired thermal power plants, cement, chemical, pharmaceutical, alumina, limestone, refinery, due to benefits such as reduced transport gas flow requirement (resulting in lower sized compressor with substantial energy savings), smaller pipeline diameter and support structures, reduced wear rate of pipeline (especially in the bends), and smaller sized gas-solids separation units. While designing a pipeline system, it is important to reliably predict the total pipeline pressure drop. Pipeline pressure drop for solids-gas flow is largely dependent on the solids contribution of the pressure drop, especially for the dense phase. Pressure drop due to solids is often represented using a dimensionless solids friction factor (Wypych 1989; Jones and Williams 2003; Williams and Jones 2004; Mallick and Wypych 2010). Due to the highly complex and turbulent nature of the moving bed of powder, power function based empirical models have been employed over the years by various researchers (Pan and Wypych

Address correspondence to: S. S. Mallick, Department of Mechanical Engineering, Thapar University, Patiala, Punjab147004, India. E-mail: soumyasuddha@rediffmail.com
1998; Jones and Williams 2003; Williams and Jones 2004; Mallick and Wypych 2010) for straight-pipe pressure drop. These models have provided good results when applied to the researchers' own data. However, recent investigations by Mallick (2010) to examine the scale-up accuracy and stability of these existing model formats by comparing the predicted conveying characteristics against experimental data have shown that they generally provide inaccuracy for scale-up conditions of pipeline length and/or diameter. Therefore, there is a need for a more in-depth study of the pressure drop characteristics of solids-gas flow through a straight-pipe section (or the straight-pipe pneumatic conveying characteristics; PCC). Over the years, most of the conveying characteristics that have been published in the literature for fine powders are based on total pipeline pressure drop (Wypych 1989; Mills 2004; Ratnayake and Datta 2007). Little work has been reported for straight-pipe conveying characteristics for fine powders in fluidized dense phase, which may reveal useful information on the flow mechanism (such as dense-to-dilute-phase flow transition). With such background, the main purpose of this article is to investigate the straight-pipe conveying characteristics for different powders, pipelines, and pipeline tapping points (different diameter and lengths of pipe and location of 
tapping points in the pipeline) and achieve a better understanding of the flow characteristics of fluidized dense-phase pneumatic conveying of fine powders.

\section{Experimental Setup}

Test data from the following products were used in this study:

a) fly ash and

b) white powder.

Table 1 lists some physical properties of these products.

Power station fly ash was conveyed through $69 \mathrm{~mm}$ I.D. $\times 168 \mathrm{~m}, 105 \mathrm{~mm}$ I.D. $\times 168 \mathrm{~m}$ and $69 \mathrm{~mm}$ I.D. $\times 554 \mathrm{~m}$ long pipelines at the Bulk Material Handling Laboratory of the University of Wollongong, Australia. A schematic of the test set up for the $69 \mathrm{~mm}$ I.D. $\times 168 \mathrm{~m}$ long pipline is shown in Figure 1. This test rig comprised:

- tandem $0.9 \mathrm{~m}^{3}$ bottom-discharge blow tank feeding system;

- $69 \mathrm{~mm}$ I.D. $\times 168 \mathrm{~m}$ long mild steel pipeline, including $7 \mathrm{~m}$ vertical lift, five $1 \mathrm{~m}$ radius $90^{\circ}$ bends and $150 \mathrm{~mm}$ N.B. tee-bend connecting the end of the pipeline to the feed bin;

- $6 \mathrm{~m}^{3}$ receiving bin with insertable pulse-jet dust filter;

- all necessary instrumentation: load cells on feed bin and receiving bin, annubar with differential pressure meter, static pressure measurements via two sets of tapping locations on the straight-pipe lengths: P9-P10 $(52.68 \mathrm{~m}$ apart) and P11-P12 (40.41 m apart). P8 is located at the beginning of the conveying pipe and is meant to provide the total pipeline pressure drop; pressure tapping points

Table 1. Physical properties of the test products

\begin{tabular}{lccc}
\hline Product & $\rho_{\mathrm{p}}\left(\mathrm{kg} / \mathrm{m}^{3}\right)$ & $\rho_{\mathrm{bl}}\left(\mathrm{kg} / \mathrm{m}^{3}\right)$ & $\mathrm{d}_{50}{ }^{*}(\mu \mathrm{m})$ \\
\hline Fly ash & 2300 & 700 & 30 \\
White podwer & 1600 & 620 & 55 \\
\hline
\end{tabular}

${ }^{*} \mathrm{~d}_{50}$ : median particle size (measured by laser diffraction analyzer).

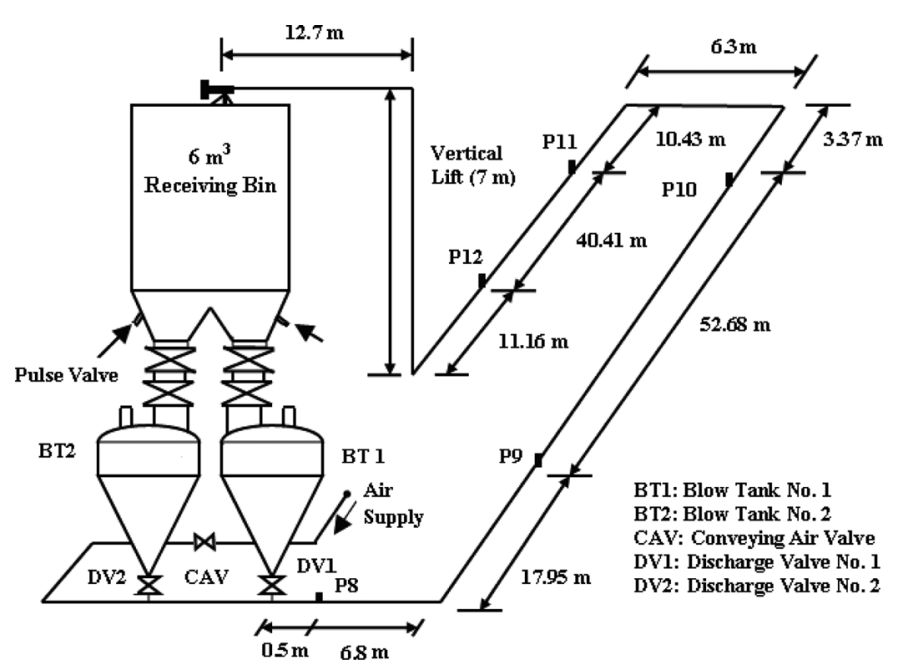

Fig. 1. Layout of the $69 \mathrm{~mm}$ I.D. $\times 168 \mathrm{~m}$ long test rig.
P1-P7 are placed at various points on the pressurized air supply line and on blow tank.

- data acquisition unit for data recording and analysis.

A schematic of the test set up for the $105 \mathrm{~mm}$ I.D. $\times 168 \mathrm{~m}$ and $69 \mathrm{~mm}$ I.D. $\times 554 \mathrm{~m}$ long pipes are shown in Figures A1 and A2 (see Appendix A).

The fine "white powder" was conveyed through another test rig (as shown in Figure A3).

The test facility comprised:

- $0.5 \mathrm{~m}^{3}$ bottom-discharge blow tank feeding system;

- $69 \mathrm{~mm}$ I.D. $\times 148 \mathrm{~m}$ long mild steel pipeline, including $4 \mathrm{~m}$ vertical lift, six $1 \mathrm{~m}$ radius $90^{\circ}$ bends;

- static pressure measurements via two sets of tapping locations on the straight-pipe lengths: P9-P10 (53.1 m apart) and $\mathrm{P} 11^{+}-\mathrm{P} 12$ (19.9 $\mathrm{m}$ apart); the tapping locations were similar to that of the fly ash test rig (described previously), except the new tapping $\mathrm{P}_{1} 1^{+}$was introduced almost mid-way between P11 and P12.

- "sight glass" just after the P12 location (approximate length of $1 \mathrm{~m}$ ) for flow visualization. Other arrangements were similar to that of the fly ash rigs.

\section{Straight-Pipe Pneumatic Conveying Characteristics}

\subsection{Fly Ash}

Using steady-state straight-pipe pressure drop data for a range of solids and air flow rates through P9-P10 and P11P12 tapping points for the $69 \mathrm{~mm}$ I.D. $\times 168 \mathrm{~m}$ long pipe, the following straight-pipe PCC were obtained (Figure 2). PCC for individual tapping points P9-P10 and P11-P12 were superimposed on the same plot for the purpose of comparing the characteristics with respect to tapping point locations (i.e., along the flow direction or pipe length). Constant mean Froude number and superficial air velocity lines for individual PCC are also shown.

Figure 2 shows that between 0.04 and $0.08 \mathrm{~kg} / \mathrm{s}$ of airflow, the pressure gradient (and slopes of PCC) are greater for P9-P10 data than those for the P11-P12 data. The solid

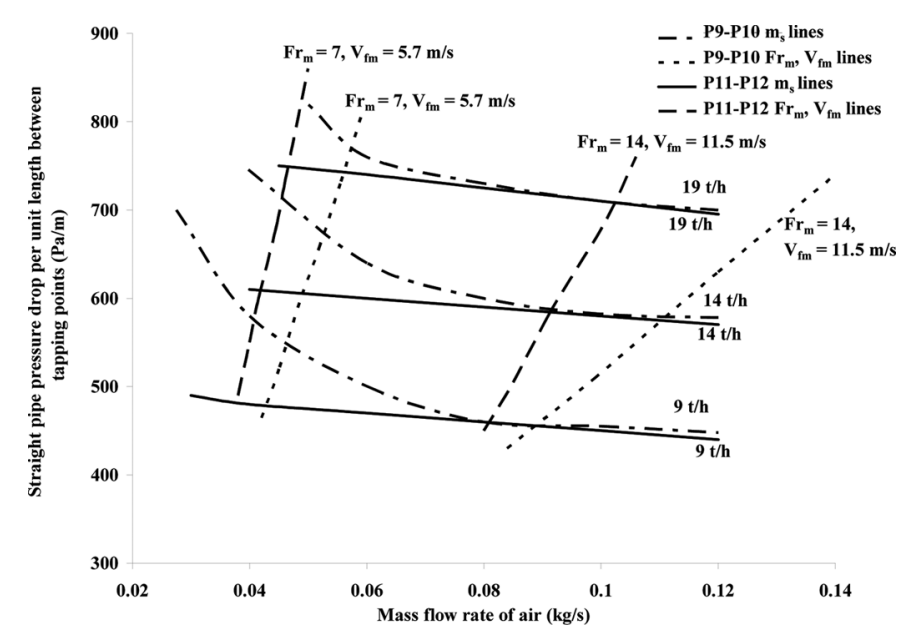

Fig. 2. Comparison of PCC for straight-pipe pressure (P9-P10 versus P11-P12), fly ash, $69 \mathrm{~mm}$ I.D. $\times 168 \mathrm{~m}$ long pipe. 
flow lines for initial tappings (P9-P10) show a change in trends in solids flow lines (e.g., corresponding to $\mathrm{Fr}_{\mathrm{m}}=7$ line for the $19 \mathrm{t} / \mathrm{h}$ curve). However, the same solid flow lines for final tappings (P11-P12) show no change in trend (compared to that shown by P9-P10 PCC) for the same range of air flow rates $(0.04-0.08 \mathrm{~kg} / \mathrm{s})$. From 0.08 to $0.12 \mathrm{~kg} / \mathrm{s}$, both sets of PCC have continued on with almost the same trend (gradual pressure decrease) and similar pressure drop values. It must also be appreciated that no clear pressure minimum curve (PMC) was observed in either set of PCC, indicating a gradual change in flow characteristics (with respect to air flow). In contrast, distinct pressure minimum lines are observed for granular products, (Marcus et al. 1990). Using steadystate straight-pipe pressure drop data through P9-P10 and P11-P12 tapping points for the $105 \mathrm{~mm}$ I.D. $\times 168 \mathrm{~m}$ long pipe, the following straight-pipe PCC have been obtained (Figure 3).

Figure 3 shows that between 0.06 and $0.11 \mathrm{~kg} / \mathrm{s}$ of airflow, both the P9-P10 than P11-P12 PCC show a substantial change in trend. From a significantly decreasing pressure gradient for air flows $\mathrm{Fr}_{\mathrm{m}} \leq 7$, the PCC have become almost horizontal thereafter (for both P9-P10 and P11-P12 data sets). P9-P10 PCC have provided consistently higher values of pressure gradient than those for the P11-P12 PCC. No clear PMC (PMC) was observed in either set of PCC. Using steady-state straight-pipe pressure drop data through P9P10 and P11-P12 tapping points for the $69 \mathrm{~mm} \mathrm{I.D.} \times 554 \mathrm{~m}$ $\mathrm{m}$ long pipe, the following straight-pipe $\mathrm{PCC}$ have been obtained (Figure 4).

Figure 4 shows none of the PCC provides a sharp change in slope. The P9-P10 PCC show a gradually decreasing slope (only minor change in slope), while the P11-P12 PCC show a slight change in trend (slight downward slope to the left of $\mathrm{Fr}_{\mathrm{m}}=13$ line and slight upward slope to the right of the same line). The change in slope may be an indication of change in flow characteristics along the flow direction. However, there was no distinct PMC in either set of PCC, indicating that even if there were a flow transition (change in flow mechanism from dense-to-dilute phase), the change is

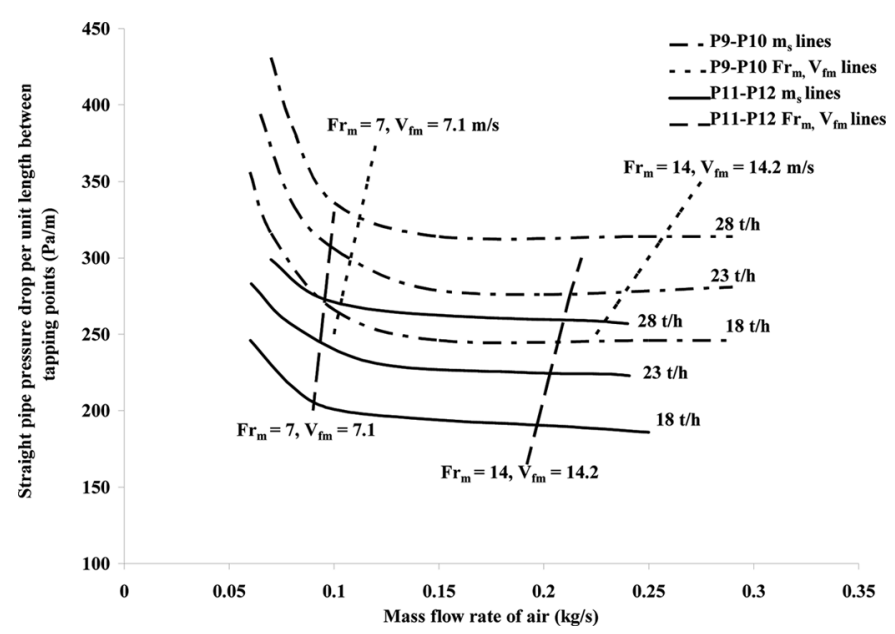

Fig. 3. Comparison of PCC for straight-pipe pressure (P9-P10 versus P11-P12), fly ash, $105 \mathrm{~mm}$ I.D. $\times 168 \mathrm{~m}$ long pipe.

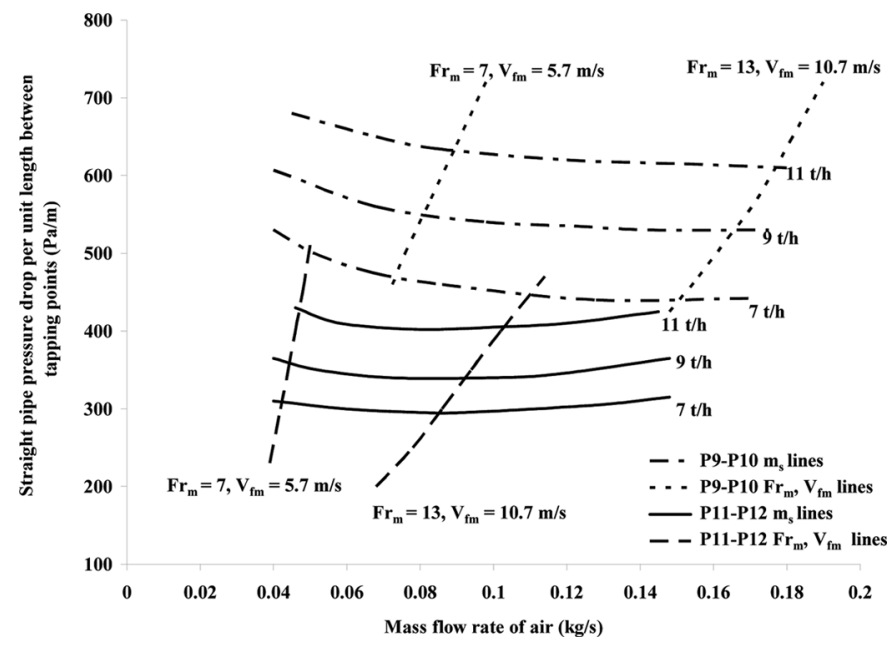

Fig. 4. Comparison of PCC for straight-pipe pressure (P9-P10 versus P11-P12), fly ash, $69 \mathrm{~mm}$ I.D. $\times 554 \mathrm{~m}$ long pipe.

very gradual. P9-P10 PCC have provided consistently higher values of pressure gradient than those for P11-P12 PCC.

\subsection{White Powder}

Using steady-state straight-pipe pressure drop data for a range of solids and air flows through $\mathrm{P} 9-\mathrm{P} 10$ and $\mathrm{P}^{+} 1^{+}$ P12 tapping points for the $69 \mathrm{~mm}$ I.D. $\times 148 \mathrm{~m}$ long pipe, the following straight-pipe PCC have been obtained (Figure 5). PCC for individual tapping points P9-P10 and $\mathrm{P} 11^{+}-\mathrm{P} 12$ have been superimposed on the same plot for the purpose of comparing the characteristics with respect to tapping point locations (i.e., along the flow direction or pipe length).

Figure 5 shows there is significant change in slope of the PCC with increasing air flow rates. From 0.04 to $0.12 \mathrm{~kg} / \mathrm{s}$ of air flow, pressure drop decreases with increase in air flow rates. From 0.12 to $0.2 \mathrm{~kg} / \mathrm{s}$, PCC for P9-P10 become almost horizontal (i.e., no appreciable change in pressure gradient even with increasing air flow). For the same range of air flows $(0.12-0.2 \mathrm{~kg} / \mathrm{s}), \mathrm{PCC}$ for $\mathrm{P} 11^{+}-\mathrm{P} 12$ show a noticeable

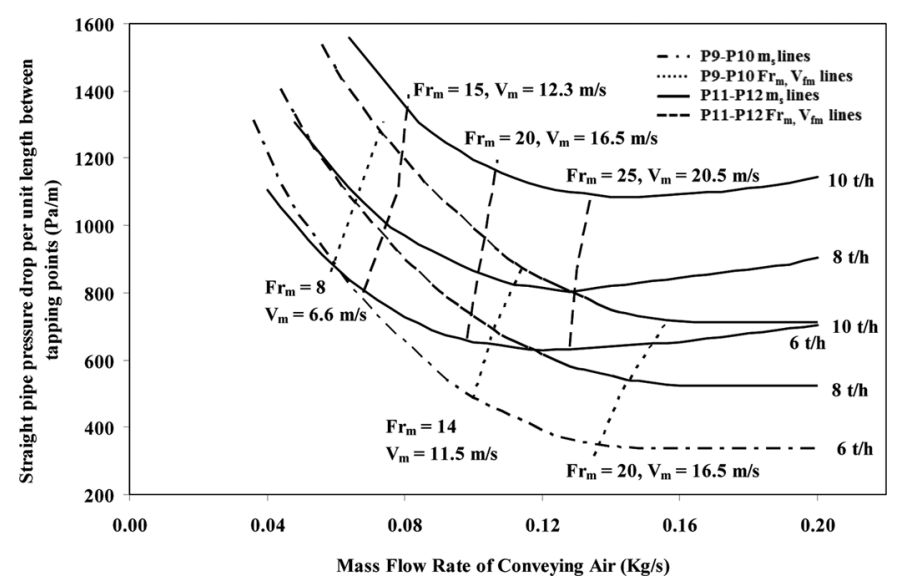

Fig. 5. Comparison of PCC for straight-pipe pressure (P9-P10 versus $\mathrm{P} 11^{+}$-P12), white powder, $69 \mathrm{~mm}$ I.D. $\times 148 \mathrm{~m}$ long pipe. 
upward trend (i.e., pressure drop starts to increase with increasing air flow rates). Flow visualization (through sight-glass) during the test program showed that up to an air flow rate of approximately $0.12 \mathrm{~kg} / \mathrm{s}$, the flow of powders was in non-suspension mode (dense phase). At about 0.12 $0.13 \mathrm{~kg} / \mathrm{s}$, the flow of powders became suspended (dilute phase) and remained the same up to $0.2 \mathrm{~kg} / \mathrm{s}$. Thus, change of slope of straight-pipe PCC slope may be an indication of dense-to-dilute transition criteria. However, from the shape of PCC, it may also be appreciated that the change of such flow mechanism (i.e., dense-to-dilute transition) is a rather gradual change for fine powder conveying. The different shapes of PCC from P9-P10 and P11 ${ }^{+}$-P12 suggest that there could be changes in flow mechanism along the flow direction (flow changing from dense-to-dilute phase along the flow direction). Comparing the PCC provided in Figures 3 and 4 (fly ash) and Figure 5 (white powder) reveals that for the same solids and air flows, the pressure gradient values are greater in the pipeline initial tapping points (P9-P10) than the later (P11-P12) for fly ash, while the reverse happens for white powder (pressure gradients obtained from $\mathrm{P} 11^{+}$ $\mathrm{P} 12$ are greater than those obtained from P9-P10 for white powder). This indicates the flow complexity and modeling challenges for dense phase pneumatic conveying of different powders as powders can behave quite differently and unexpectedly under actual flow conditions. This also emphasizes the requirement of pilot-plant testing and scaling up the test information to industrial situation, rather than making assumptions regarding product behavior that can lead to drastically wrong predictions (especially when scaled up).

\section{Modeling Dense- to Dilute-Phase Transition Criteria}

Dense-to-dilute phase transition criteria is generally represented by the location of PMC in the straight-pipe PCC (Marcus et al. 1990). A list of models for prediction of PMC (i.e., the dense-to-dilute-phase transition criteria) is provided in the following. Because of the relatively distinct location of pressure minima for coarser particles compared to fine powders (the change in flow mechanism from dense to dilute phase is gradual for fine powders, that is, no distinct location of PMC for fine powders), majority of the previous efforts to model PMC were limited to only coarser particles. These models have been evaluated in the following to investigate into their predictive capability for fine powders. The lower boundary of dilute-phase flow of coarser particles (i.e., at the initiation of saltation of particles) is represented by the PMC (Marcus et al. 1990; Yi et al. 1998).

\subsection{Existing Models}

Rose and Duckworth (1969) investigated the minimum conveying velocity within a pipeline of $32 \mathrm{~mm}$ diameter by conveying mustard seed, glass bead, lead bead and steel bead and developed the following correlation for minimum conveying velocity for dilute phase (which corresponds to the PMC; Marcus et al. 1990):

$$
V_{\min }=2.33 G_{s}^{0.286} D^{0.5} d^{-0.857} \rho_{p}^{-1} \rho^{0.714} U_{t}^{1.43} .
$$

Matsumoto (1974) (reported in Ratnayake 2005) investigated the minimum conveying velocity with pipelines for $29 \mathrm{~mm}$ and $49 \mathrm{~mm}$ in diameter using glass bead, copper bead and polystyrene as the test materials and provided the following model for minimum velocity for dilute phase:

$$
V_{\min }=3.4 \sqrt{g D}\left(\frac{\rho}{\rho_{p}}\right)^{0.294}\left(\frac{U_{t}}{\sqrt{g d}}\right)^{1.02} m^{* 0.277} .
$$

Rizk (1976) provided the following model (Equation (3)) for PMC by conveying Sryropor and Polystrol through pipelines having $50-400 \mathrm{~mm}$ diameters.

$$
m^{*}=\frac{1}{10^{\delta}} F r_{\min } \chi,
$$

where

$$
\begin{gathered}
\delta=1.44 d+1.96 \\
\chi=1.1 d+2.5 .
\end{gathered}
$$

Weber (1981) provided correlation for minimum conveying velocity as provided in Equations (6) and (7). Weber (1981), however, did not clearly indicate whether the models are applicable for both fine and coarse particles.

For $U_{t} \leq 3 \mathrm{~m} / \mathrm{s}$

$$
F r_{i}=\left[7+\frac{8}{3} U_{t}\right] m^{* 0.25}\left(\frac{d}{D}\right)^{0.1} .
$$

For $U_{t} \geq 3 \mathrm{~m} / \mathrm{s}$

$$
F r_{i}=15 m^{* 0.25}\left(\frac{d}{D}\right)^{0.1} .
$$

Schade (1987) investigated minimum conveying velocity for a number of diameters (50 to $150 \mathrm{~mm}$ ) and test materials (such as granule, sand, styropor, rubber, and polystyrol) and provided the following correlation:

$$
V_{\min }=2.8 G_{s}^{0.1} D^{0.428} d^{-0.023} \rho_{p}^{0.306} \rho^{-0.405} .
$$

Cabrejos and Klinzing (1994) investigated minimum conveying velocity by conveying alumina, glass beads and for polyester polymers through a pipeline of $50 \mathrm{~mm}$ diameter. Their model to indicate PMC was:

$$
\frac{V_{\min }}{\sqrt{g d}}=\frac{U_{t}}{\sqrt{g d}}+0.00224\left(\frac{\rho_{p}}{\rho}\right)^{1.25}\left(m^{*}\right)^{0.5} .
$$

Kalman et al. (2005) presented a pickup velocity model (Equations (10) to (12)) using a modified Reynolds number $\left(\operatorname{Re}_{p}^{*}\right)$ and Archimedes number term by conveying glass, zirconium, alumina, iron, salt sand, talk and ammonium oxide.

For $\mathrm{Ar}>16.5$

$$
\mathrm{Re}_{p}^{*}=5 A r^{\frac{3}{7}} .
$$

For $0.45<\mathrm{Ar}<16.5$

$$
\operatorname{Re}_{p}^{*}=16.7 .
$$


For $\operatorname{Ar}<4.5$

$$
\mathrm{Re}_{p}^{*}=21.8 A r^{\frac{1}{3}}
$$

\subsection{New Model Development}

A new model for PMC has been developed using Buckingham $\pi$ theorem (Cengel et al. 2003). The model is evaluated for fly ash (particle density as $2300 \mathrm{~kg} / \mathrm{m}^{3}$, bulk density as $700 \mathrm{~kg} / \mathrm{m}^{3}$ and $\mathrm{d}_{50}^{*}$ as $30 \mu \mathrm{m}$ ) and white powder (particle density: $1600 \mathrm{~kg} / \mathrm{m}^{3}$, bulk density: $620 \mathrm{~kg} / \mathrm{m}^{3}$ and $\mathrm{d}_{50}: 55 \mu \mathrm{m}$ ). The models are provided in Equations (13) and (14).

For fly ash,

$$
\mathrm{Re}_{p}=8.027 A r^{1.001} .
$$

For white powder,

$$
\mathrm{Re}_{p}=1.694 A r^{1.004},
$$

where

$$
\begin{gathered}
\operatorname{Re}_{p}=\frac{\rho d V_{P M C}}{\mu} \\
A r=\frac{\rho^{2} d^{3} g\left(\rho_{p}-\rho\right)}{\mu^{2} \rho} .
\end{gathered}
$$

\subsection{Evaluation of Models}

The existing and new models have been evaluated on the straight-pipe PCC of fly ash and white powder for the following pipe sections (PCC in which the solids lines of the straight-pipe pressure drops exhibited change in trends; i.e., "U'-shaped curve):

- P11-P12 tappings of 69 mm I.D. $\times 554 \mathrm{~m}$ long pipe for fly ash;

- P11 ${ }^{+}$-P12 tappings of $69 \mathrm{~mm}$ I.D. $\times 148 \mathrm{~m}$ long pipe for white powder.

The results are shown in Figures 6 and 7.

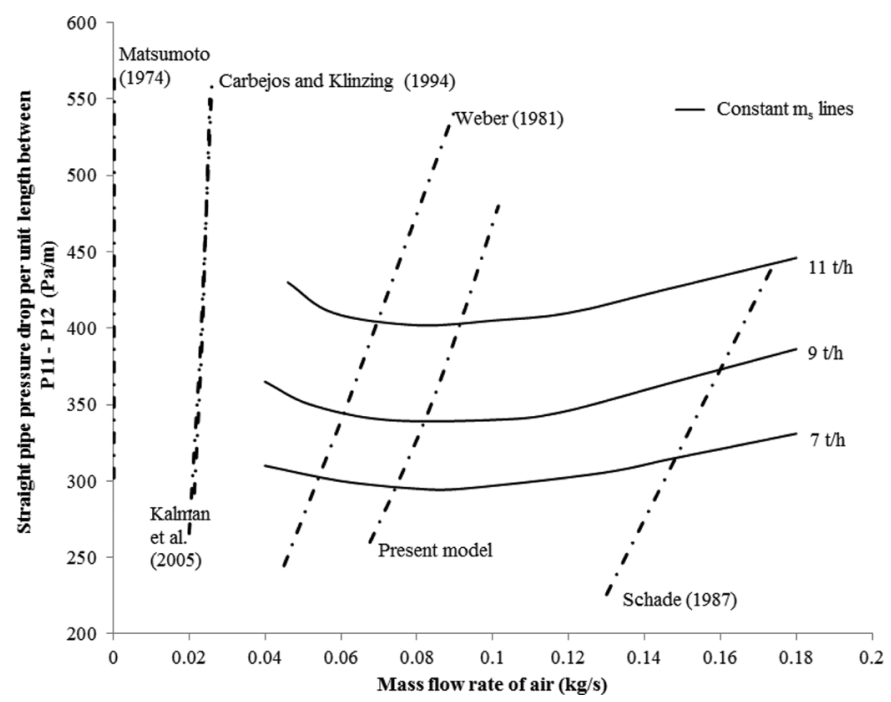

Fig. 6. Evaluation of models for PMC on straight-pipe PCC, fly ash, P11-P12, 69 mm I.D. $\times 554 \mathrm{~m}$ long pipe.

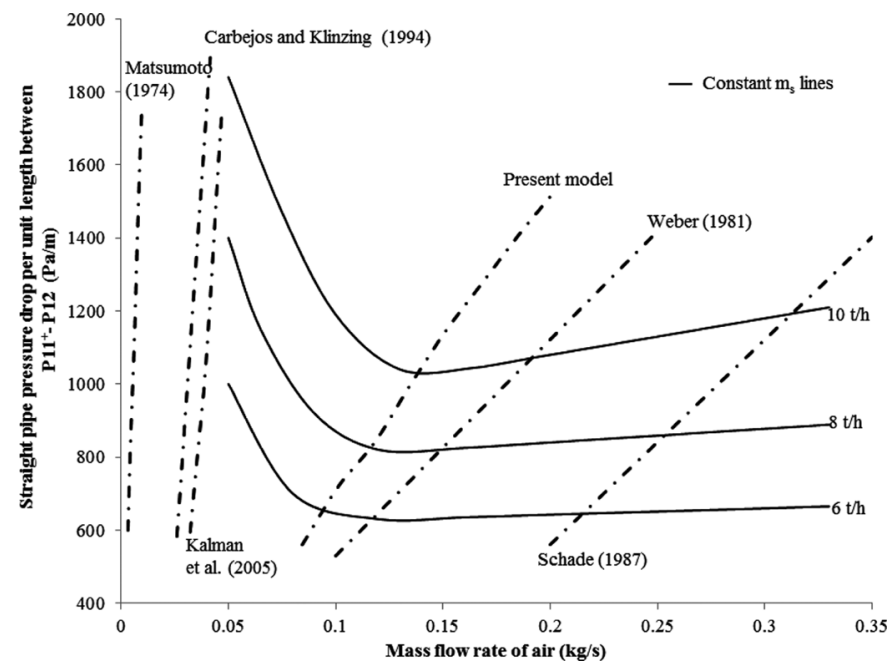

Fig. 7. Evaluation of models for PMC on straight-pipe PCC, white powder, P11 ${ }^{+}$-P12, $69 \mathrm{~mm}$ I.D. $\times$ nbsp;148 m long pipe.

Figure 6 shows that Kalman et al. (2005), Cabrejos and Klinzing (1994), and Matsumoto (1974) models significantly under-predicts PMC (i.e., the predicted PMC are located at very low air flow rates that are below the range of conveying conditions). In fact, the predictions using Matsumoto model are drastically low (almost coinciding with the Y-axis). Weber (1981) provided good predictions (i.e., the predicted PMC are very close to the range of experimental pressure minimum points). Schade (1987) provided considerable over-predictions (i.e., the predicted PMC are located to the right of the experimental pressure minimum points). Figure 7 shows that Kalman et al. (2005), Cabrejos and Klinzing (1994) and Matsumoto (1974) models significantly underpredict PMC. Schade (1987), again, provides considerable over-predictions, whereas, predictions with Weber's (1981) model, though provides some over-predictions, but are closer to the experimental points compared to that obtained by Schade (1987). Predictions using Rose and Duckworth (1969) and Rizk (1976) were found to be out of domain of the plot (large deviation for experimental plots), hence the same have not been shown in Figures 6 and 7.

\section{Solids Friction Factor Models}

The loss of pressure for the flow of solids-gas mixture through a horizontal straight-pipe section can be calculated using equation 15 (Barth 1958). This equation indicates that other parameters being constant, pressure drop through a pipe section increases with an increase in pipe length and decrease of pipe diameter.

$$
\Delta \mathrm{P}=\left(\lambda_{\mathrm{f}}+\mathrm{m}^{*} \lambda_{\mathrm{s}}\right) \mathrm{L} / \mathrm{D} \rho \mathrm{V}^{2} / 2 .
$$

From the steady-state straight-pipe pressure drop data, the following models for solids friction factor have been generated using regression analysis by commercially available software. The solids friction factor models obtained from different pipe and tapping data for fly ash are listed in Table 2. 
Table 2. Solids friction factor models for fly ash

\begin{tabular}{lll}
\hline $\begin{array}{l}\text { Pipeline } \\
\text { (I.D. } \times \text { length) }\end{array}$ & $\begin{array}{c}\text { Straight-pipe } \\
\text { section }\end{array}$ & \multicolumn{1}{c}{$\lambda_{\mathrm{s}}$ model } \\
\hline $69 \mathrm{~mm} \times 168 \mathrm{~m}$ & $\mathrm{P} 9-\mathrm{P} 10$ & $\lambda_{\mathrm{s}}=21.82 \mathrm{~m}^{*-0.74} \mathrm{Fr}_{\mathrm{m}}^{-2.09}$ \\
& $\mathrm{P} 11-\mathrm{P} 12$ & $\lambda_{\mathrm{s}}=3 \mathrm{~m}^{*-0.45} \mathrm{Fr}_{\mathrm{m}}^{-1.7}$ \\
$105 \mathrm{~mm} \times 168 \mathrm{~m}$ & $\mathrm{P} 9-\mathrm{P} 10$ & $\lambda_{\mathrm{s}}=13.8 \mathrm{~m}^{*-0.72} \mathrm{Fr}_{\mathrm{m}}^{-2.11}$ \\
& $\mathrm{P} 11-\mathrm{P} 12$ & $\lambda_{\mathrm{s}}=4.91 \mathrm{~m}^{*-0.6} \mathrm{Fr}_{\mathrm{m}}^{-1.9}$ \\
$69 \mathrm{~mm} \times 554 \mathrm{~m}$ & $\mathrm{P} 9-\mathrm{P} 10$ & $\lambda_{\mathrm{s}}=10.47 \mathrm{~m}^{*-0.74} \mathrm{Fr}_{\mathrm{m}}^{-1.96}$ \\
& $\mathrm{P} 11-\mathrm{P} 12$ & $\lambda_{\mathrm{s}}=3.39 \mathrm{~m}^{*-0.51} \mathrm{Fr}_{\mathrm{m}}^{-1.84}$ \\
\hline
\end{tabular}

Table 2 shows that all the developed models are different depending on pipeline and tapping location. In all the pipelines, the absolute values of $\mathrm{K}$, $\mathrm{a}$, and $\mathrm{b}$ for the models generated from the P9-P10 tapping data are greater than those obtained from the P11-P12 data. This difference of developed models depending on pipeline and tapping location suggests that the flow mechanisms for dense phase flow of fine powders vary for different pipe diameters and lengths, as well as with difference in tapping location (indicating a possible change in flow mechanism along the direction of flow). These variations of developed models seem to support the difference of straight-pipe PCC discussed before (Figures 2-4).

\subsection{Influence of Bends on Pneumatic Conveying Characteristics}

To investigate the relative influence of straight-pipe sections, bends and verticals on the location of the PMC on the total pipe PCC, PCC for the following different sections of the $69 \mathrm{~mm}$ I.D. $\times 168 \mathrm{~m}$ long pipe have been compared for fly ash conveying (see Figures 8-10):

a) between pressure tappings P9 and P11 (pipe length: $72.78 \mathrm{~m}$, having $2 \times 90$ degree bends);

b) between pressure tapping P11 and exit to the pipe (pipe length: $71.27 \mathrm{~m}$, having $2 \times 90$ degree bends and a $7 \mathrm{~m}$ vertical lift);

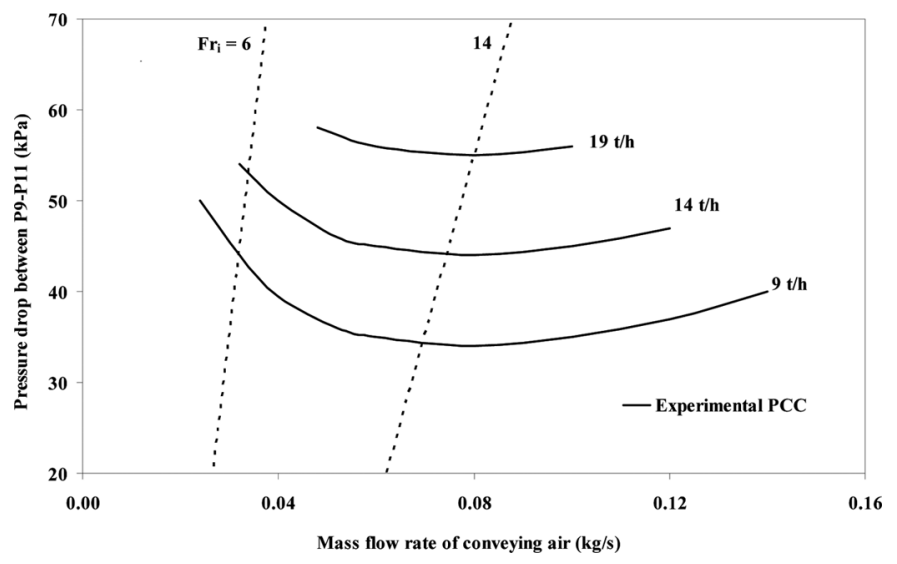

Fig. 8. PCC for pressure tappings P9-P11 (pipe Length: $72.78 \mathrm{~m}$, having $2 \times 90$ degree bends) for fly ash and $69 \mathrm{~mm}$ I.D. $\times 168 \mathrm{~m}$ pipe.

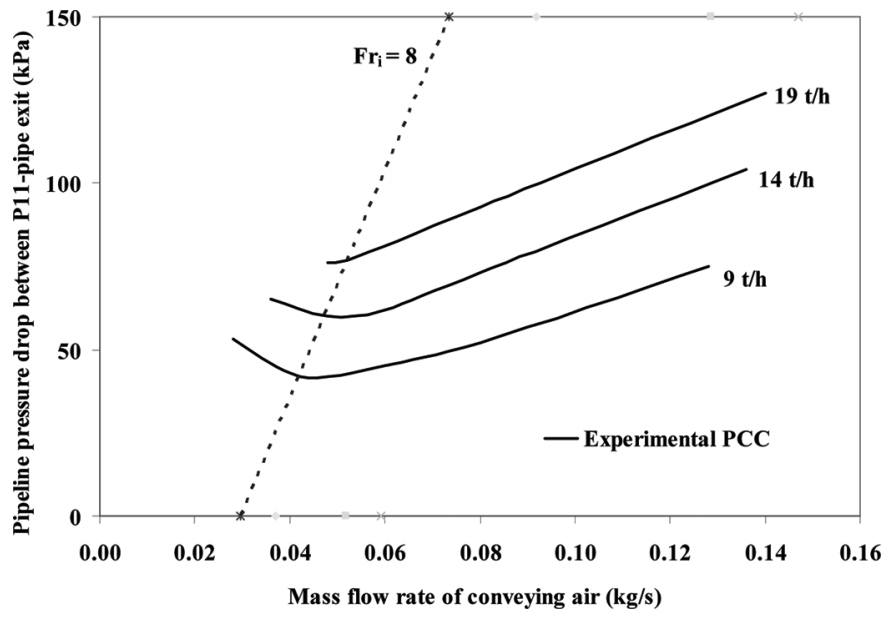

Fig. 9. PCC between pressure tapping P11 and pipe exit (pipe length: $71.27 \mathrm{~m}$, having $2 \times 90$ degree bends and a $7 \mathrm{~m}$ vertical lift) for fly ash, $69 \mathrm{~mm}$ I.D. $\times 168 \mathrm{~m}$ pipe.

c) between pressure tapping P12 and exit to the pipe (pipe length: $30.86 \mathrm{~m}$, having $2 \times 90$ degree bends and a $7 \mathrm{~m}$ vertical lift).

Initial Froude number lines (Froude number at inlet to the section) have been superimposed on the section PCC (Figures 8-11).

The results show that each pipe segment has its own PCC, the shape of which depends on the location of that pipe segment (i.e., location of pressure tappings) with respect to the total pipe length and also on the effect of any bends and verticals included in the segment. The pressure drop decreases or remains almost constant with an increase in the mass flow rate of air (within the tested range of air flow), as shown previously in Figures 2, respectively for sections with only "straight-pipe" lengths, whereas, inclusion of bends and verticals have resulted in " $U$ "-shaped PCC or sharply rising pressure drop characteristics (Figures 8-10). Figure 11 shows the combined effect of having straight pipe (for a small length) and two closely spaced bends. The trend

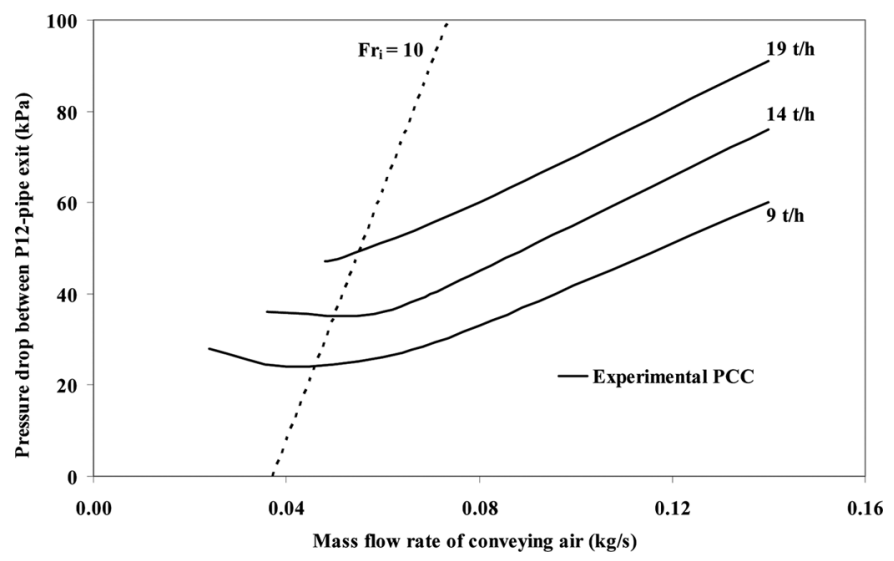

Fig. 10. PCC between pressure tapping P12 and exit to the pipe (pipe length: $30.86 \mathrm{~m}$, having $2 \times 90$ degree bends and a $7 \mathrm{~m}$ vertical lift) for fly ash and $69 \mathrm{~mm}$ I.D. $\times 168 \mathrm{~m}$ pipe. 


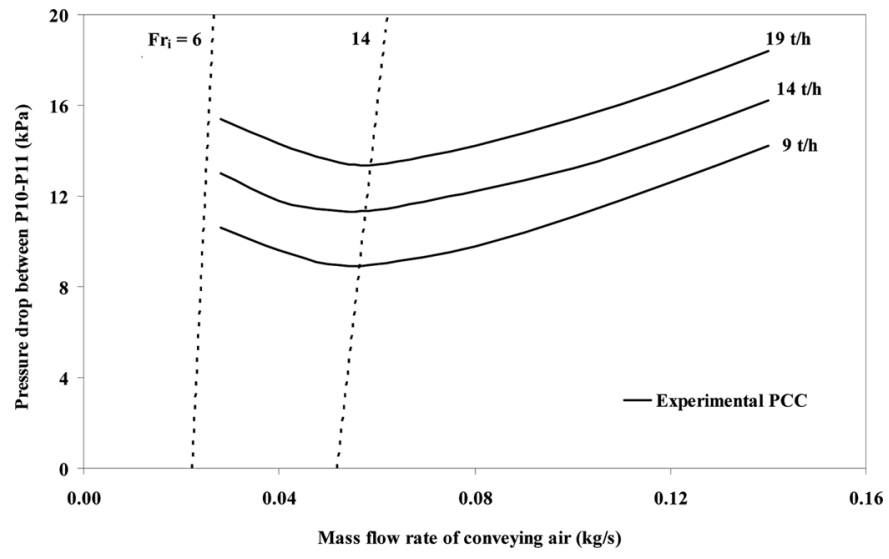

Fig. 11. PCC between pressure tapping P10 and P11 (pipe length: $10.1 \mathrm{~m}$, having $2 \times 90$ degree bends) for fly ash and $69 \mathrm{~mm}$ I.D. $\times 168 \mathrm{~m}$ pipe.

of this PCC shows "U"-shaped characteristics. The trend of increasing pressure drop with an increase in air mass flow rate is believed to have been contributed by the bend pressure loss characteristics. The PCC for the total pipe is a superimposition of the PCC of the individual pipe segments. As a result, the shape of the total pipeline PCC will depend on the relative contribution of the pressure drop characteristics of each of the individual pipe segments (such as horizontal straight pipe, bends, and verticals) -for example, adding more bends to a system is expected to produce more sharply rising pressure drop characteristics toward the dilute-phase regime. This is to cause a shift of the PMC (for total pipeline) toward the left. This emphasizes that while PMC for total pipeline PCC may be of interest from an industrial design point of view (optimum operating point), but the PMC line (for total pipeline PCC) should not be used as an indicator for dense- to dilute-phase transition criteria, as the location of PMC is largely affected by the number and position of bends in the pipeline.

\section{Conclusion}

Based on the results presented in this chapter, it can be concluded that even for the same product, straight-pipe PCC can be different depending on pipeline diameter or length and location of pressure tapping points on the same pipeline. This indicates that the flow mechanism changes along the flow direction. Straight-pipe PCC obtained from initial tapping points in the pipeline (P9-P10) have generally shown steeper PCC than those obtained further along the pipeline (P11-P12). The models derived for solids friction factor for fly ash from different straight-pipe sections of three different pipes were found to be all different (e.g., different values of power function constants and exponents). This indicates the highly product and pipeline dependent characteristics of fluidized dense-phase conveying of fine powders. There was no distinct PMC in any of the straight-pipe PCC, indicating that even if there were a flow transition (change in flow mechanism from dense-to-dilute phase), the change was very gradual. The nature of the "U"-shape and location of the PMC for the total pipeline PCC are significantly influenced by the pipeline layout (e.g., location and number of bends) and not entirely by the dense- to dilute-phase transition of flow mechanism. To account for the change in flow characteristics along the flow direction (such as dense-todilute phase) future research may be carried out by employing different models for different regimes (as the flow phenomena of dense and dilute phases are very different: nonsuspension to suspension flow mode).

$\begin{array}{ll}\text { Nomenclature } \\ \mathrm{Ar} & \text { Archimedes number } \\ \mathrm{D} & \text { internal diameter of pipe }[\mathrm{m}] \\ \mathrm{d} & \text { diameter of particle }[\mathrm{m}] \\ \mathrm{Fr} & \text { Froude number based on gas velocity }=\mathrm{V} / \sqrt{ }(\mathrm{gD}) \\ \mathrm{G}_{\mathrm{s}} & \text { product mass flow rate per unit area, } \mathrm{G}_{\mathrm{s}}=\mathrm{m}_{\mathrm{s}} / \mathrm{A} \\ & {\left[\mathrm{kg} / \mathrm{s}^{2} \mathrm{~m}^{2}\right]} \\ \mathrm{g} & \text { acceleration due to gravity }\left[\mathrm{m} / \mathrm{s}^{2}\right] \\ \mathrm{L} & \text { length of pipe section }[\mathrm{m}] \\ \mathrm{m}_{\mathrm{f}} & \text { mass flow rate of air }[\mathrm{kg} / \mathrm{s}] \\ \mathrm{m}_{\mathrm{s}} & \text { mass flow rate of solids }[\mathrm{kg} / \mathrm{s}] \\ \mathrm{m}^{*} & \text { solid loading ratio }=\mathrm{m}_{\mathrm{s}} / \mathrm{m} \\ \Delta \mathrm{P} & \text { pressure drop due to solids and air }[\mathrm{Pa}] \\ \mathrm{Re} & \text { particle Reynolds number } \\ \mathrm{U}_{\mathrm{t}} & \text { terminal velocity }[\mathrm{m} / \mathrm{s}] \\ \mathrm{V} & \text { superficial air velocity for the test section }[\mathrm{m} / \mathrm{s}] \\ \mathrm{V}_{\mathrm{PMC}} & \text { superficial air velocity corresponding to }[\mathrm{m} / \mathrm{s}] \\ \rho & \text { density of air }\left[\mathrm{kg} / \mathrm{m}^{3}\right] \\ \rho_{\mathrm{bl}} & \text { loose-poured bulk density }\left[\mathrm{kg} / \mathrm{m}^{3}\right] \\ \rho_{\mathrm{p}} & \text { particle density }\left[\mathrm{kg} / \mathrm{m}^{3}\right] \\ \lambda_{\mathrm{f}} & \text { friction factor due to air only } \\ \lambda_{\mathrm{s}} & \text { solid friction factor for straight pipe } \\ \mu & \text { dynamic viscosity }[\mathrm{kg} / \mathrm{m}-\mathrm{s}]\end{array}$

\section{Subscripts}

i value at the entry of pipe

fm mean fluid parameter

$\mathrm{m} \quad$ mean value for pipe section

min minimum

$\mathrm{mp} \quad$ minimum pressure

\section{Abbreviations}

$\begin{array}{ll}\text { ESP } & \text { electrostatic precipitator } \\ \text { I.D. } & \text { internal diameter of pipe } \\ \text { PCC } & \text { pneumatic conveying characteristics } \\ \text { PMC } & \text { pressure minimum curve }\end{array}$

\section{References}

Barth, W. 1958. Strömungsvorgänge beim Transport von Festteilchen und Flüssigkeitsteilchen in Gasen. Chemie Ing. Techn. 3(3): 171-180.

Cabrejos, F. J., and G. E. Klinzing 1994. Minimum conveying velocity in horizontal transport and the pickup and saltation mechanisms of solid particles. Bulk Solid Handling 14: 349-353.

Cengel, Y. A. 2003. Heat and mass transfer: A practical approach, 3rd ed. Boston: McGraw Hill.

Jones, M. G., and K. C. Williams. 2003. Solids friction factors for fluidized dense-phase conveying. Particulate Science and Technology 21: 45-56. 
Kalman, H., A. Satern, D. Meir, and E. Rabinovich. 2005. "Pickup (critical) velocities of particles. Powder Technology 160: 103-113.

Mallick, S. S. 2010. Modelling fluidised dense phase pneumatic conveying of powders. Ph.D. dissertation, University of Wollongong.

Mallick, S. S., and P. W. Wypych. 2010. An investigation into modelling of solids friction for dense-phase pneumatic conveying of powders. Particulate Science and Technology 28: 51-66.

Marcus, R. D., L. S. Leung, G. E. Klinzing, and F. Rizk. 1990. Pneumatic conveying of solids $-A$ theoretical and practical approach. London: Chapman and Hall.

Matsumoto, S., M. Hara, S. Saito, and S. Maeda. 1974. Minimum transport velocity for horizontal pneumatic conveying. Journal of Chemical Engineering of Japan 7: 425-431.

Mills, D. 2004. Pneumatic conveying design. Burlington, MA: Elsevier Butterworth-Heinemann.

Pan, R., and P. W. Wypych. 1998. Dilute and dense phase pneumatic conveying of fly ash. In Proceedings of the 6th International Conference on Bulk Materials Storage and Transportation, Wollongong, NSW, Australia, Institute of Engineers, Australia, September 28-30, pp. 183-189.

Ratnayake, C. 2005. A comprehensive scaling up technique for pneumatic transport systems. Ph.D. dissertation, Norwegian University of Sceince and Technology.

Ratnayake, C., and B. K. Datta. 2007. A unified scaling-up technique for pneumatic conveying systems. Particulate Science and Technology 25: 289-302.

Rizk, F. 1976. Pneumatic conveying at optimal operating conditions and a solution of Barth's equation $\lambda \mathrm{z}=\Phi\left(\lambda \mathrm{z}^{*}, \beta\right)$. In Proceedings of $3 \mathrm{rd}$ International Conference on the Pneumatic Transport of Solids in Pipes, Fluid Engineering, Cranfield, England, April 7-9, D4 (43-58).

Rose, H. E., and R. A. Duckworth. 1969. Transport of solid particles in liquid and gasses. The Engineer 227(5903): 392-396.

Schade, B. 1987. Zum ubergang Sprung-strahnenforderung bieder Horizontalen Pneumatischen Feststoffordrung. Ph.D. dissertation, University of Karlsruhe.

Weber, M. 1981. Principles of hydraulic and pneumatic conveying on pipes. Bulk Solids Handling 1: 57-63.

Williams, K. C., and M. G. Jones. 2004. Numerical model velocity profile of fluidised dense phase pneumatic conveying. In Proceedings of 8th International Conference on Bulk Materials Storage and Transportation, Wollongong, NSW, Australia, Australian Society for Bulk Solids Handling, July 5-8, pp. 354-358.

Wypych, P. W. 1989. Pneumatic conveying of bulk solids. Ph.D. dissertation, University of Wollongong.

Yi, J., P. W. Wypych, and R. Pan. 1998. Minimum conveying velocity in dilute-phase pneumatic conveying. Powder Handling and Processing 10(3): 255-261.

\section{Appendix A}
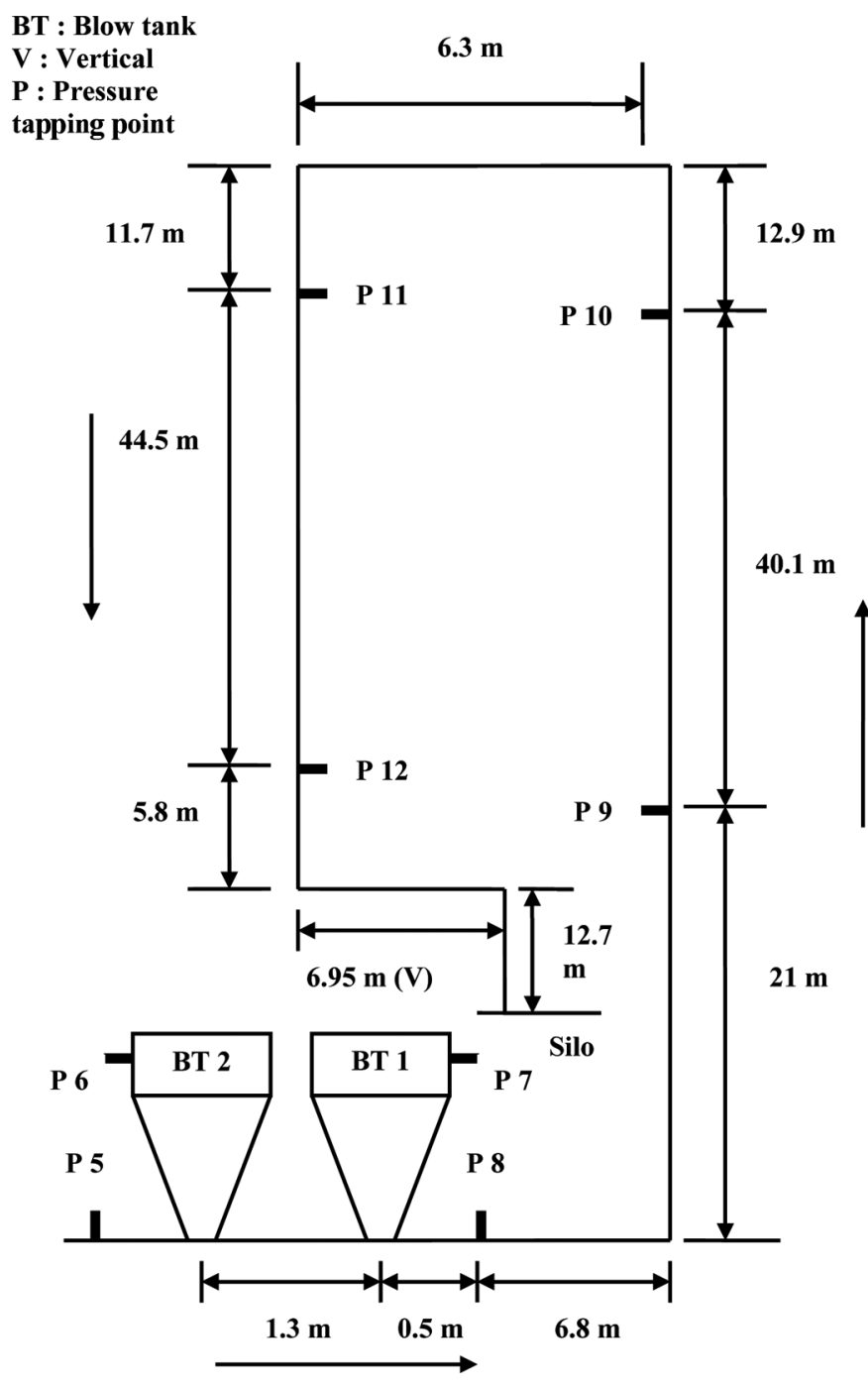

A1. Layout of the $105 \mathrm{~mm}$ I.D. $\times 168 \mathrm{~m}$ long test rig for fly ash. 


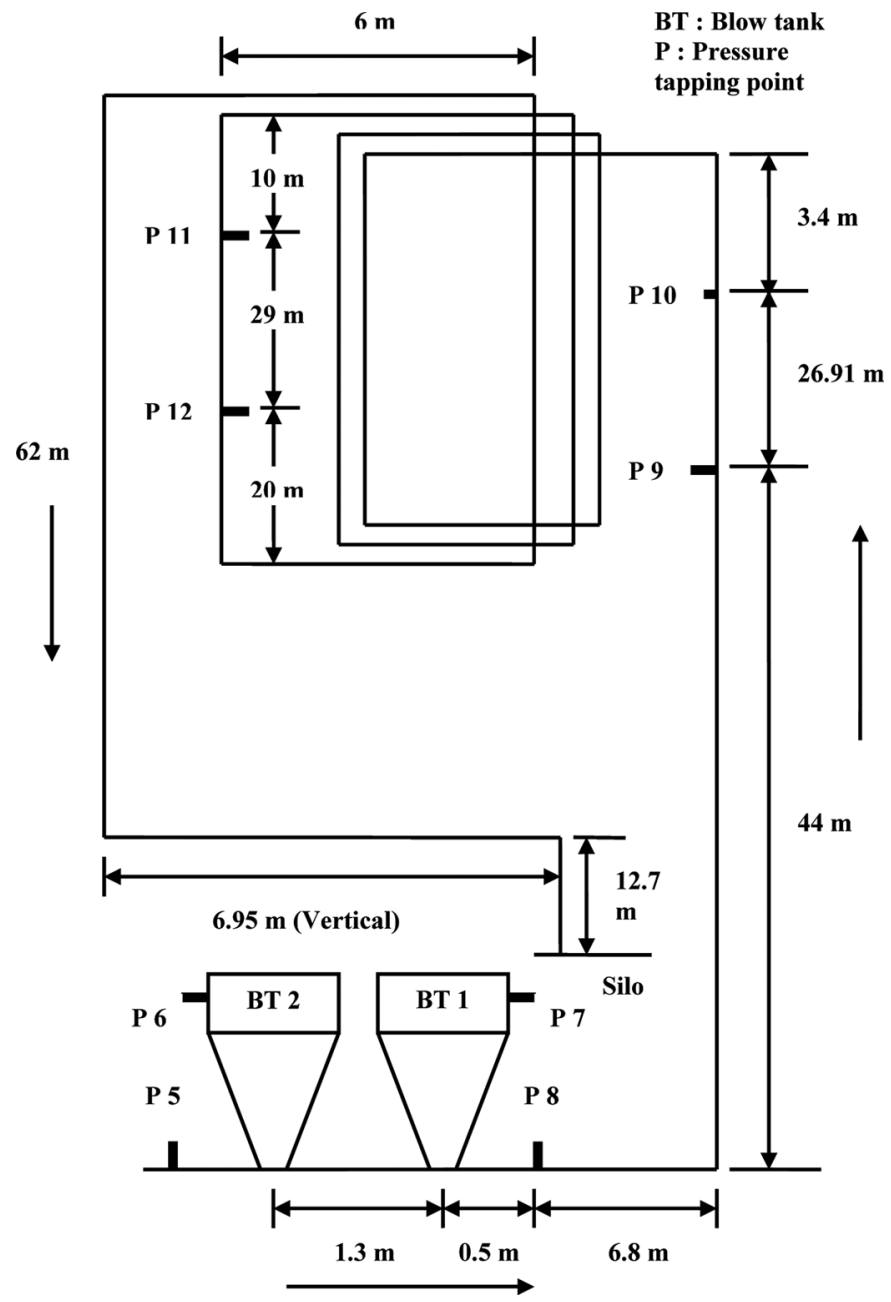

A2. Layout of the $69 \mathrm{~mm}$ I.D. $\times 148 \mathrm{~m}$ long test rig for white powder.

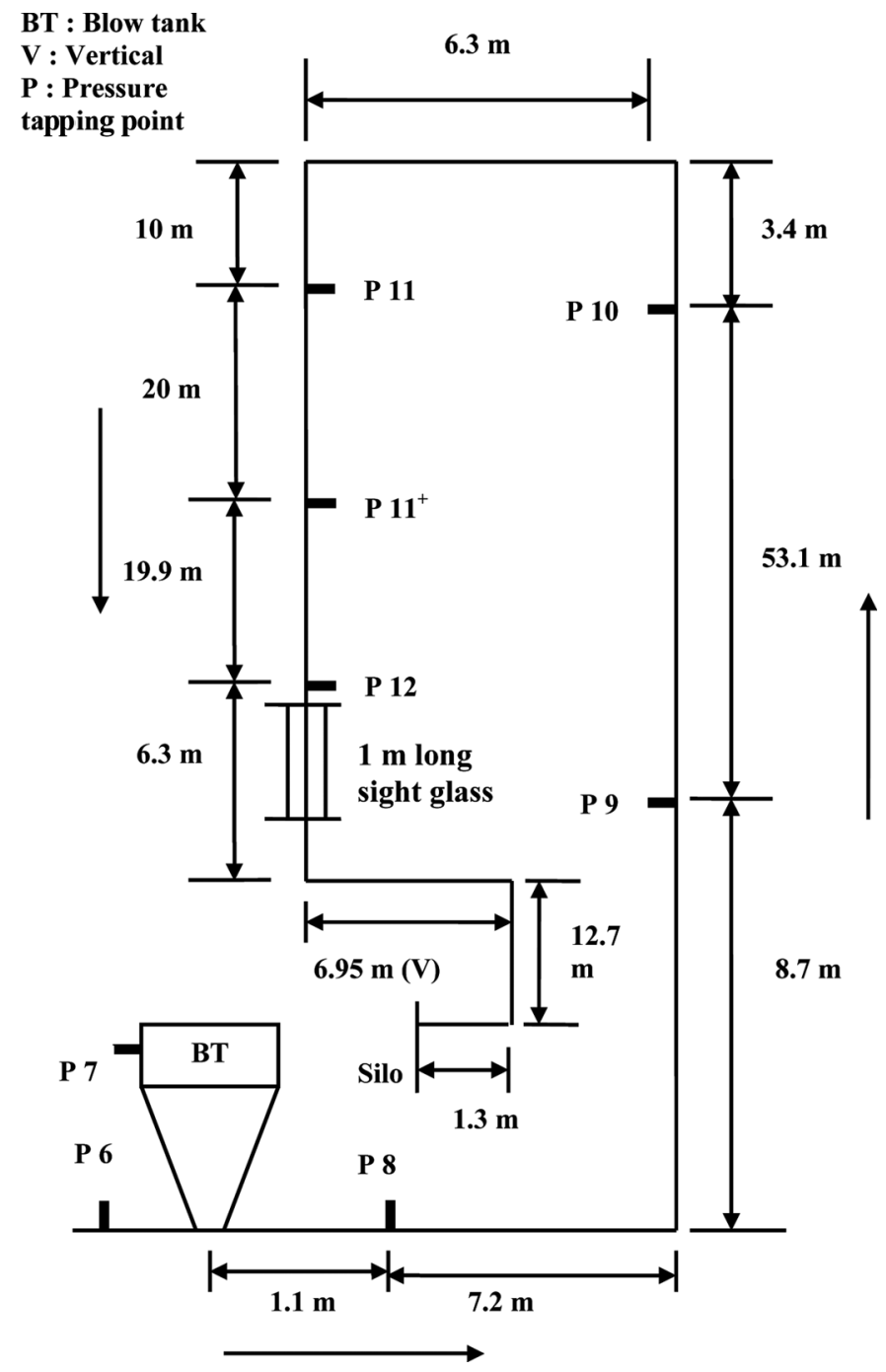

A3. Layout of the $69 \mathrm{~mm}$ I.D. $\times 148 \mathrm{~m}$ long test rig for white powder. 